\title{
EFFECT OF SEVERE PLASTIC DEFORMATION AND OXIDATION ON THE STRUCTURE AND MICROHARDNESS OF THE SILUMIN SURFACE LAYER
}

\author{
L. G. Korshunov*, N. L. Chernenko, I. G. Brodova, I. G. Shirinkina \\ M.N. Miheev Institute of Metal Physics, Ural Branch of Russian Academy of Sciences, \\ 18 S. Kovalevskoy st., Ekaterinburg, Russian Federation \\ *Corresponding author. E-mail: korshunov@imp.uran.ru; \\ address for correspondence: 18 ul. S. Kovalevskoy, 620990, Ekaterinburg, Russian Federation. \\ Tel.:+7 (343) 37837 38; fax: +7 (343) 3745244
}

Structural changes occurring in the surface layer, up to $10 \mu \mathrm{m}$ thick, of silumin $(\mathrm{Al}-17 \% \mathrm{Si}$ alloy) in the case of deformation under sliding friction and subsequent oxidation at 100 and $200{ }^{\circ} \mathrm{C}$ for 1 hour are studied by metallographic analysis, X-ray diffraction analysis and electron microscopy. Frictional deformation was carried out in air at room temperature and in liquid nitrogen (at $-196{ }^{\circ} \mathrm{C}$ ). Deformation under these conditions is shown to form a nanocrystalline structure in the surface layer of the $\mathrm{Al}-17 \% \mathrm{Si}$ alloy and to increase its microhardness by a factor of 1.8 . In the alloy surface under friction, severe plastic deformation, as well as the high affinity of oxygen to aluminum and silicon, initiates the appearance of anomalously supersaturated solid solutions of oxygen in aluminum and silicon. Oxidation of the deformed $\mathrm{Al}-17 \% \mathrm{Si}$ alloy at $100{ }^{\circ} \mathrm{C}$ for 1 hour increases its microhardness as a result of the decomposition of anomalously supersaturated solid solutions of oxygen in aluminum and silicon and the formation of their oxides.

Keywords: silumin, frictional deformation, oxidation, structure.

DOI: $10.17804 / 2410-9908.2017 .3 .006-014$

\section{References}

1. Korshunov L.G., Makarov A.V., Chernenko N.L. Nanocrystalline friction structures in steels and alloys, their mechanical and tribological properties. In: Razvitie idey akademika V.D. Sadovskogo [Developing the Ideas of Academician V.D. Sadovsky]. Ekaterinburg, Institute of Metal Physics, UB RAS, Publ., 2008, 409 p. (In Russian).

2. Dong Y., Bell T., Enhanced wear resistance of titanium surfaces by a new thermal oxidation treatment. Wear, 2000, vol. 238, pp. 131-137.

3. Korshunov L.G., Chernenko N.L. Formation of a wear-resistant nanocrystalline layer strengthened by $\mathrm{TiO}_{2}$ (Rutile) particles on the surface of titanium. Physics of Metals and Metallography, 2013, vol. 114, no. 9, pp. 789-797. DOI: 10.1134/S0031918X13070065.

4. Metin E., Inal O.T. Kinetics of layer growth and multiphase diffusion in ion nitrided titanium. Metal. Mater. Trans., 1989, vol. 20A, no. 9, pp. 1819-1832.

5. Korshunov L.G., Shabashov V.A., Chernenko N.L., Pilyugin V.P. Effect of contact stresses on the phase composition, strength, and tribological properties of nanocrystalline structures formed in steels and alloys under sliding friction. Metal Science and Heat Treatment, 2008, vol. 5, nos. 11-12, pp. 583-592. DOI: 10.1007/s11041-009-9103-2.

6. Vol A.E. Stroenie i svoistva dvoinykh metallicheskikh system [The Structure and Properties of Binary Metal Systems]. Moscow, Gosudarstvennoe Izdatelstvo Fiziko-Matematicheskoy Literatury Publ., 1959, 755 p. (In Russian).

7. Entsiklopediya neorganicheskikh materialov. Tom 1 [Encyclopedia of Inorganic Materials, vol. 1]. Kiev, Glavnaya Redaktsiya Ukrainskoy Sovetskoy Entsiklopedii Publ., 1977, 840 p. (In Russian).

8. Pugacheva N.B., Vichuzhanin D.I., Kalashnikov S.T., Ivanov A.V., Smirnov S.V., Frolova N.Yu. Studying recovery processes in a strain-hardened $\mathrm{Al}-\mathrm{Mg}-\mathrm{Mn}-\mathrm{Fe}-\mathrm{Si}$ alloy. Physics of Metals and Metallography, 2016, vol. 117, no. 9, pp. 920-926. DOI: 10.1134/S0031918X16090076. 


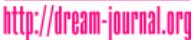

Подана в журнал: 30.06 .2017

УДК 69.715:539.4.015

DOI: $10.17804 / 2410-9908.2017 .3 .006-014$

\title{
ВЛИЯНИЕ ИНТЕНСИВНОЙ ПЛАСТИЧЕСКОЙ ДЕФОРМИЦИИ И ОКСИДИРОВАНИЯ НА СТРУКТУРУ И МИКРОТВЕРДОСТЬ ПОВЕРХНОСТНОГО СЛОЯ СИЛУМИНА
}

\author{
Л. Г. Коршунов*, Н. Л. Черненко, И. Г. Бродова, И. Г. Ширинкина \\ Федеральное государственное бюджетное учреждение науки \\ Институт физики металлов имени М.Н. Михеева Уральского отделения Российской академии наук, \\ ул. С. Ковалевской, 18, Екатеринбург, Российская Федераиция \\ *Ответственный автор. Электронная почта: korshunov@imp.uran.ru; \\ адрес для переписки: ул. С. Ковалевской, 18, Екатеринбург, Российская Федерация. \\ Тел.: +7 (343) 378-37-38; факс: +7 (343) 374-52-44
}

Методами металлографии, рентгеноструктурного анализа и электронной микроскопии исследованы структурные изменения, происходящие в поверхностном слое толщиной до 10 мкм силумина (сплава $\mathrm{Al}-17 \% \mathrm{Si}^{1}$ ) при деформировании в условиях трения скольжения и последующем оксидировании при 100 и $200{ }^{\circ} \mathrm{C}$ в течение 1 ч. Фрикционное деформирование осуществляли на воздухе при комнатной температуре и в среде жидкого азота (при $-196^{\circ} \mathrm{C}$ ). Показано, что деформирование в рассматриваемых условиях формирует в поверхностном слое сплава $\mathrm{Al}-17$ \% Si нанокристаллическую структуру и повышает его микротвердость в 1,8 раз. Интенсивная пластическая деформация, а также большое сродство кислорода к алюминию и кремнию инициируют возникновение в поверхностном слое сплава при трении аномально пересыщенных твердых растворов кислорода в алюминии и кремнии. Оксидирование при $100{ }^{\circ} \mathrm{C}$ (1 ч) деформированного сплава $\mathrm{Al}-17$ \% Si повышает его микротвердость в результате распада аномально пересыщенных твердых растворов кислорода в алюминии и кремнии и образования их окислов.

Ключевые слова: силумин, фрикичионное деформирование, оксидирование, структура.

\section{1. Введение}

Комбинированные технологии упрочняющих обработок поверхности металлических материалов, включающие различные способы больших (наноструктурирующих) деформаций и термические воздействия, вызывают в настоящее время значительный технический интеpec. Они способны обеспечивать рост уровня физико-механических свойств нанокристаллических материалов, улучшение их служебных характеристик, в том числе снижение коэффициента трения, способность к приработке, повышение чистоты упрочняемой поверхности и др. $[1,2]$. Показано, что большая пластическая деформация поверхностного слоя металлических материалов, имеющая место в условиях трения скольжения, характеризуется активным развитием ротационных механизмов пластичности, которые в конечном счете приводят к образованию нанокристаллического структурного состояния в слое толщиной порядка 10 мкм $[1,5]$. Чрезвычайно высокая дефектность данного состояния, характеризующаяся наличием протяженных границ, экстремально высокой плотности дислокаций и вакансий в приграничных зонах, активизирует протекание диффузионных процессов в поверхностном слое деформированных трением материалов при их последующем нагреве. Обнаружено [3-5], что деформированные при трении нанокристаллические поверхностные слои титана, никелида титана и никеля активно насыщаются атомами кислорода воздуха, которые, далее вступая в

\footnotetext{
${ }^{1}$ здесь и далее состав указан в массовых процентах.
}

Korshunov L.G. et. al. / Effect of severe plastic deformation and oxidation on the structure and

microhardness of the silumin surface layer 
реакцию с металлом, образуют нанокристаллические частицы окислов $\left(\mathrm{TiO}_{2}, \mathrm{NiO}\right)$. После часовой выдержки в воздушной среде при $450-650{ }^{\circ} \mathrm{C}$ количество указанных высокопрочных фаз может достигать десятков объемных процентов, что вызывает рост микротвердости и сопротивления изнашиванию поверхности рассматриваемых материалов. Существенный интерес представляет изучение возможности создания на поверхности алюминиевого сплава (силумина) слоя, подобного высокопрочному металлу - оксида нанокристаллической структуры, посредством механико-термической обработки, включающей деформацию в условиях трения скольжения и последующую химико-термическую обработку - оксидирование. Этот важный вопрос еще не получил должного рассмотрения в специальной литературе. Настоящая статья посвящена исследованию влияния больших деформаций, реализующихся при трении скольжения на воздухе и в криогенной среде (жидком азоте), а также последующего оксидирования в воздушной среде, на структуру и микротвердость алюминиевого сплава $\mathrm{Al}-17 \% \mathrm{Si}$ и технически чистого алюминия. Интерес к трибологическим испытаниям исследуемых материалов в жидком азоте обусловлен возможностью подавления в данном случае диффузионных процессов и инициирования ротационных механизмов пластической деформации в поверхностном слое, что может оказать существенное влияние на формирование структуры и физико-механических свойств алюминия и его сплавов.

\section{2. Материал и методика}

Цилиндрические заготовки диаметром 20 мм силумина после отливки, электроискровой резки, механического шлифования и электролитического полирования в хлорноуксусном электролите (1:10) имели размер $7 \times 7 \times 3$ мм и микротвердость 590 МПа. Заэвтектический сплав $\mathrm{Al}-17$ \% Si имел двухфазное строение, характеризующееся наличием (Al-Si) эвтектики и первичных кристаллов кремния (рис. 1).

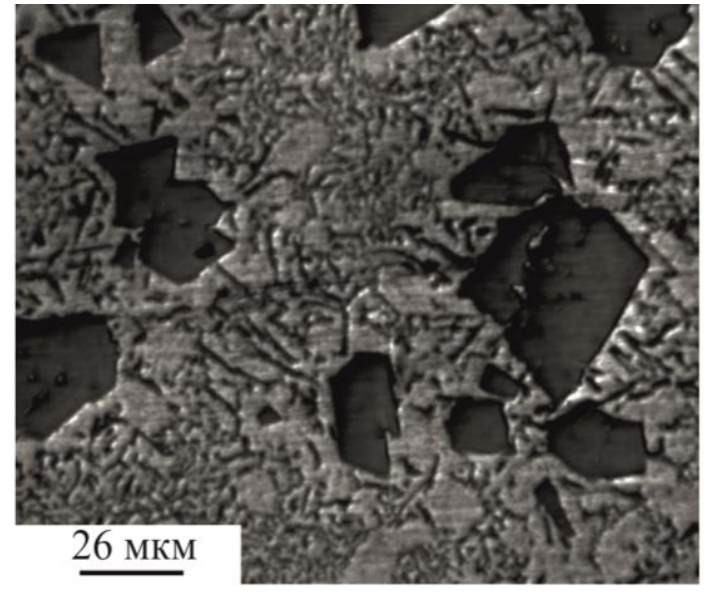

$a$

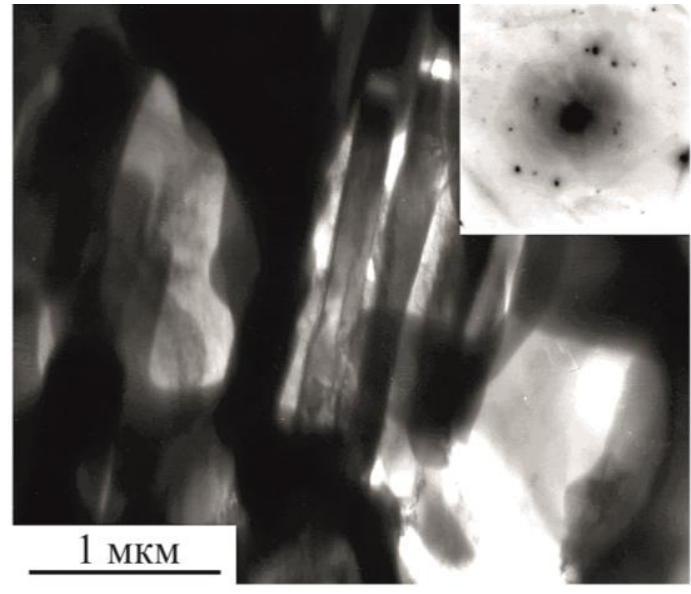

$\sigma$

Рис. 1. Структура сплава Al-17 \% Si: оптическая металлография (a); электронная микрофотография (б)

Микротвердость материала измеряли на приборе ПМТ-3 при нагрузке 0,2 $H$ и определяли как среднее арифметическое из 10 параллельных измерений, выполненных при условии сохранения геометрии отпечатка (пирамидки Виккерса). Образцы деформировали при двукратном сканировании их рабочей поверхности $(7 \times 7$ мм) скользящим (возвратно-поступательное движение) цилиндрическим индентором из кубического нитрида бора диаметром 7 мм и высотой 5 мм. Рабочую поверхность образцов шлифовали механически по 8 классу шероховатости $\left(R_{\mathrm{a}}=0,5\right.$ мкм). Фрикционное деформирование образцов выполняли без смазки на воздухе при комнатной температуре, а также в жидком

Korshunov L.G. et. al. / Effect of severe plastic deformation and oxidation on the structure and 
азоте $\left(-196{ }^{\circ} \mathrm{C}\right)[1,3]$. Длина рабочего хода индентора составляла 7 мм, нормальная нагрузка $98 \mathrm{H}$, средняя скорость скольжения - 0,014 м/с, поперечное смещение образца за один двойной ход индентора - 0,12 мм, общее число циклов нагружения - 100. Фрикционный нагрев образцов отсутствовал вследствие малой скорости скольжения индентора. Оксидирование поверхности образцов осуществлялось посредством их часового отжига в воздушной среде. Образцы далее охлаждались на воздухе до комнатной температуры.

Электронно-микроскопическое исследование материалов выполнено на микроскопе JEM-200CX методом тонких фольг, а также на сканирующем микроскопе «Quanta-200» с приставкой EDAX. Приготовление фольг осуществляли посредством одностороннего и двухстороннего электролитического полирования в струе хлорно-уксусного (1:10) электролита заготовок толщиной 70 мкм, полученных путем электроискровой резки и тонкого механического шлифования. Рентгеноструктурный анализ проводили на дифрактометре ВИП 2-50-60М в $\mathrm{CuK \alpha -излучении,} \mathrm{а} \mathrm{также} \mathrm{на} \mathrm{дифрактометре} \mathrm{ДРОН-0,5} \mathrm{в} \mathrm{Fe} K \alpha$-излучении. Методом рентгеноструктурного анализа определяли фазовый состав материалов до и после деформационной и термической обработок, параметры кристаллической решетки алюминия и кремния. Степень дефектности структуры оценивалась по уширению рентгеновских линий алюминиевой матрицы. Обработку дифрактограмм и расчеты проводили с помощью программ HighScore Plus, Outset и Profile.

\section{3. Результаты и обсуждение}

Измерения микротвердости, выполненные непосредственно на рабочей поверхности образцов, показали, что микротвердость поверхности двухфазного сплава $\mathrm{Al}-17$ \% $\mathrm{Si}$ в результате воздействия трения на воздухе и в жидком азоте возросла соответственно до 1100 и 1150 МПа, таким образом, твердость хрупкого сплава Al-17 \% Si возросла в 1,8 раза.

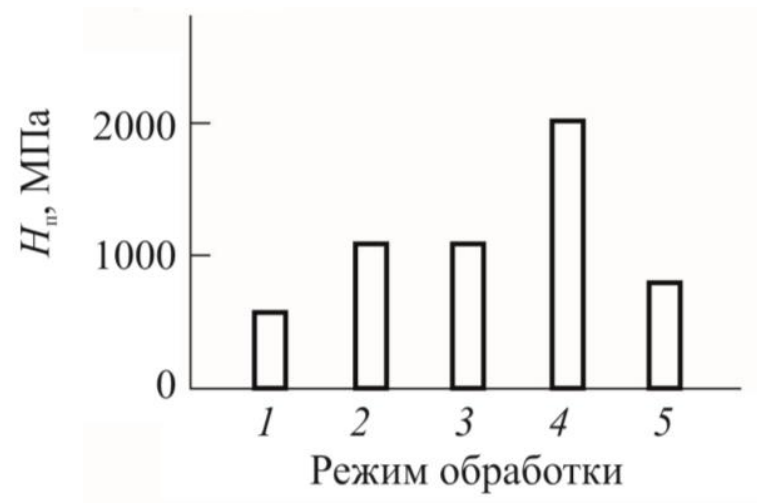

Рис. 2. Гистограмма, иллюстрирующая влияние режима обработки на микротвердость поверхности $H_{\text {п }}$ сплава Al-17\% Si: 1 - недеформированное состояние; 2 - трение в воздушной среде при комнатной температуре; 3 - трение в жидком азоте, 4 - трение на воздухе + оксидирование при $100{ }^{\circ} \mathrm{C}, 1$ ч; 5 - трение на воздухе + оксидирование $200{ }^{\circ} \mathrm{C}, 1$ ч

По результатам просвечивающей электронной микроскопии (рис. 3) видно, что трение скольжения в воздушной среде и в жидком азоте формирует в сплаве $\mathrm{Al}-17 \% \mathrm{Si}$ нанокристаллическую структуру с размером зерен от нескольких до 100 нм. Ранее было показано [1, 3], что подобная дефектная высокопрочная структура возникает при трении скольжения практически любых металлических материалов, включая хрупкие аморфные сплавы, в их деформированном слое толщиной до 10 мкм. Возникновение рассматриваемой структуры трения обусловлено спецификой напряженного состояния, создающегося в зоне фрикционного металлического контакта и характеризующегося совместным действием в деформируемом слое высоких локальных сдвиговых и сжимающих напряжений. Такое напряженное состояние вызывают развитие в зоне трения преимуще- 
ственно ротационного механизма пластичности $[1,3]$, который характеризуется относительными разворотами нанокристаллов на большие углы. По сравнению с трением на воздухе, при понижении температуры деформации фиксируется лишь небольшое (на 50-100 МПа) повышение микротвердости исследуемых материалов, т. е. криогенная температура мало влияет на упрочнение силумина. Таким образом, наблюдаемая в деформированном трением сплаве $\mathrm{Al}-17$ \% Si нанокристаллическая структура (рис. 3), а также высокий уровень ее дефектности и упрочнения можно считать типичными для строения поверхностного слоя многих металлических материалов, подвергнутых фрикционному воздействию.

Влияние оксидирования, осуществляемого в процессе часового отжига при 100 и $200{ }^{\circ} \mathrm{C}$ в воздушной среде, на микротвердость силумина, подвергнутого деформационному воздействию трения, иллюстрируют гистограмма и электронные микрофотографии, приведенные на рис. 2 и 3.

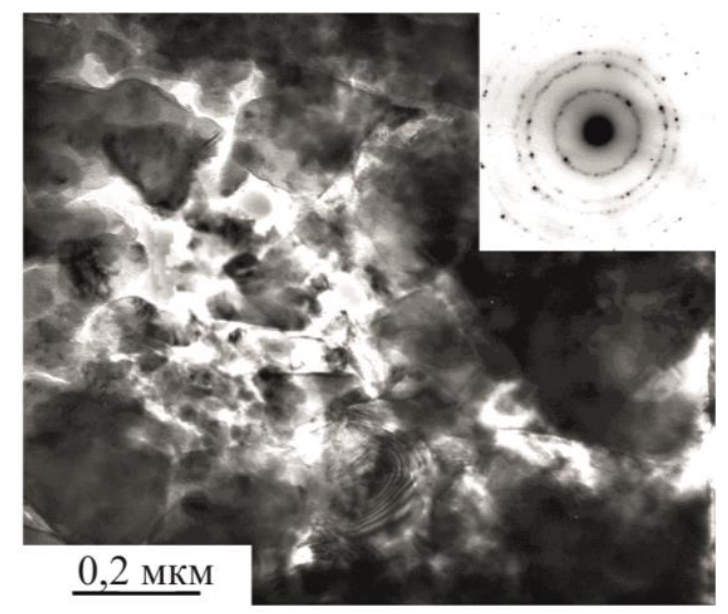

$a$

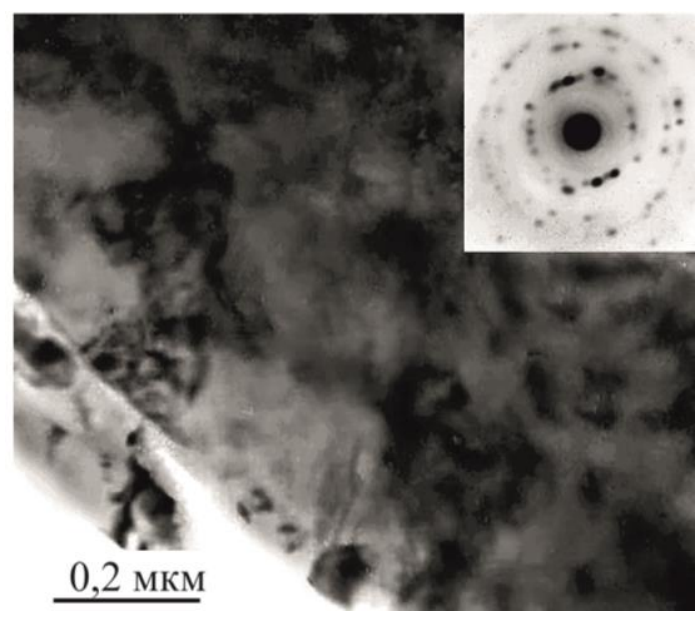

B

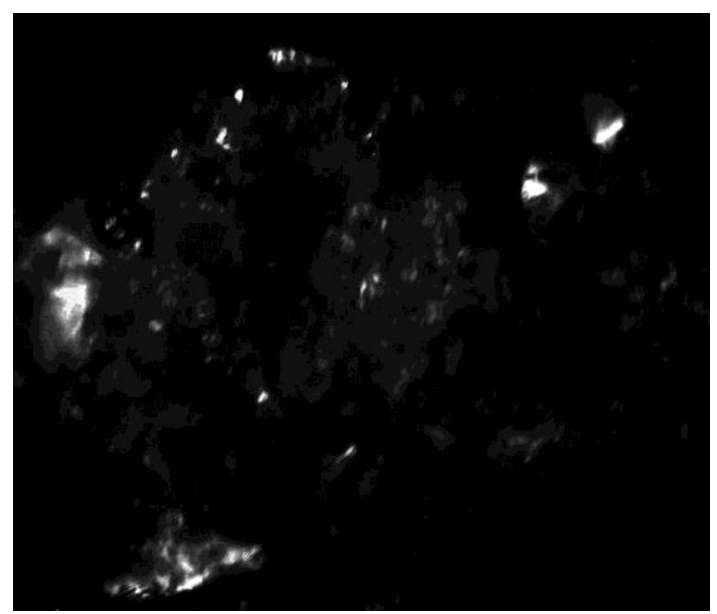

$\sigma$

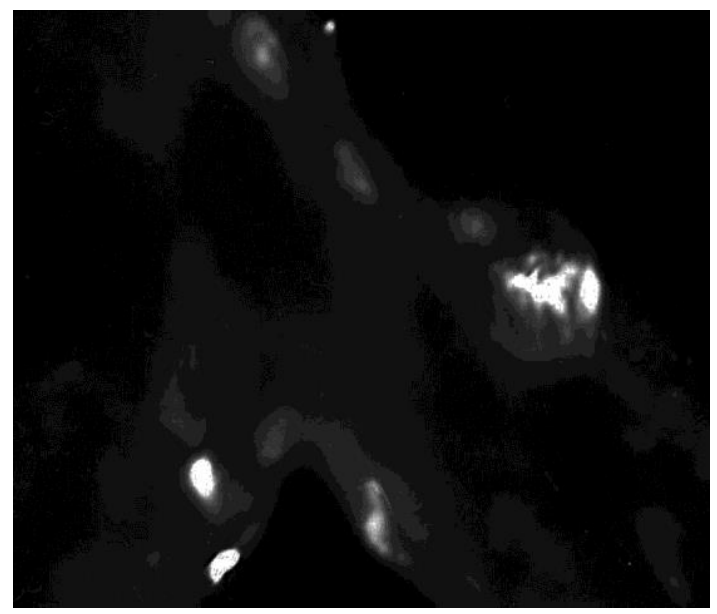

2

Рис. 3. Структура поверхностного слоя сплава $\mathrm{Al}-17 \% \mathrm{Si}$, подвергнутого деформированию в условиях трения скольжения: на воздухе $(a, \sigma)$ и в жидком азоте $(6,2)$.

Светлопольные $(a, b)$ и темнопольные $(\sigma, 2)$ в рефлексе $(111) \gamma$ изображения

Оксидирование при $100{ }^{\circ} \mathrm{C}, 1$ ч примерно в 1,8 раза повышает микро-твердость поверхности сплава Al-17\% Si, деформированного трением (рис. 2). Увеличение температуры оксидирования до $200{ }^{\circ} \mathrm{C}$ вызывает падение микротвердости исследуемого сплава до $\sim 800$ МПа, что ниже уровня твердости поверхности деформированного

Korshunov L.G. et. al. / Effect of severe plastic deformation and oxidation on the structure and 
сплава. В сплаве $\mathrm{Al}-17 \% \mathrm{Si}$, содержащем большое количество (десятки объемных процентов) нанокристаллических частиц твердого (микротвердость $\sim 10$ ГПа) теплостойкого (температура плавления $-1415{ }^{\circ} \mathrm{C}$ ) кремния (рис. 1 и 2), при 100-градусном оксидировании термическое разупрочнение еще не получило развития активно происходящее при более высокой температуре оксидирования $\left(200{ }^{\circ} \mathrm{C}\right)$ (рис. 2) [8]. Наличие значительного упрочнения сплава $\mathrm{Al}-17 \% \mathrm{Si}$ при оксидировании $100^{\circ} \mathrm{C}$ (1 ч) подтверждает, что в рассматриваемых условиях деформирования в сплаве происходят процессы ускоренного диффузионного насыщения кислородом. При этом в поверхностном слое сплава формируются метастабильные аномально пересыщенные твердые растворы кислорода в алюминии и кремнии, которые далее при нагреве частично распадаются с образованием нанооксидов алюминия и кремния, обусловливая рост микротвердости отожжённого сплава.

Результаты микрорентгеноспектрального анализа показали при обеих температурах оксидирования высокую ( 15 \% по массе) концентрацию кислорода в деформированном трением поверхностном слое, толщиной порядка нескольких микрон. Пересыщение сплава по кислороду можно объяснить совместным действием двух основных факторов: 1 - ускоренным диффузионным перемещением атомов кислорода, происходящим в условиях экстремально большой деформации и формирования нанокристаллической структуры; 2 - сильным сродством кислорода к алюминию и кремнию. Из-за ограниченной растворимости кислорода в алюминии и кремнии, атомы кислорода способны перемещаться лишь по дефектам - границам нанозерен, вакансиям и дислокациям, образуя в матрице сплава локальные микрообъемы с повышенным содержанием кислорода. Отжиг при 100 и $200{ }^{\circ} \mathrm{C}$ деформированного сплава $\mathrm{Al}-17$ \% Si приводит к значительному (до 5 \%) снижению содержания кислорода в его поверхностном слое, что связанно с выделением из матрицы сплава, растворенного ранее при деформации кислорода. Данный распад пересыщенных твердых растворов кислорода в алюминии и кремнии, очевидно, инициирован снижением дефектности матрицы сплава в результате ее термического разупрочнения (возврат, рекристаллизация). Таким образом, хотя растворимость кислорода в алюминии и кремнии чрезвычайно мала [9], в нанокристаллической дефектной матрице сплава происходит образование аномально пересыщенных твердых растворов кислорода в алюминии и кремнии.

Эффект подтверждается результатами рентгеноструктурного анализа, согласно которым, трение приводит к уширению линий на дифрактограмме (например, полная ширина линии (222) А1 на середине высоты увеличивается по сравнению с исходным состоянием на 0,05 град.) и значительному росту параметра кристаллической решетки Al-фазы от $a=0,40495$ нм (недеформированное состояние) до $a=0,40565$ нм после деформирования трением.

Одновременно с изменением параметра решётки алюминия в деформированном сплаве наблюдается рост значений параметра решётки кремния, что может служить косвенным доказательством частичного внедрения в неё атомов кислорода. Из рис. 4 видно, что на дифрактограммах сплава, подвергнутого деформированию и последующему оксидированию при 100 и $200{ }^{\circ} \mathrm{C}\left(1\right.$ ч), со стороны малых углов у линий $(111)_{\mathrm{Al}}$ и $(200)_{\mathrm{Al}}$ появляются дополнительные пики, которые могут одновременно принадлежать модифицированной алюминиевой матрице, а также оксиду алюминия. Так, например, $d_{111}(\mathrm{Al})=0,233$ нм, a $d_{10-1}\left(\mathrm{Al}_{2} \mathrm{O}_{3}\right)=0,237 \mathrm{HM} ; d_{200}(\mathrm{Al})=0,202 \mathrm{HM}$, a $d_{102}\left(\mathrm{Al}_{2} \mathrm{O}_{3}\right)=0,208 \mathrm{HM}$. 


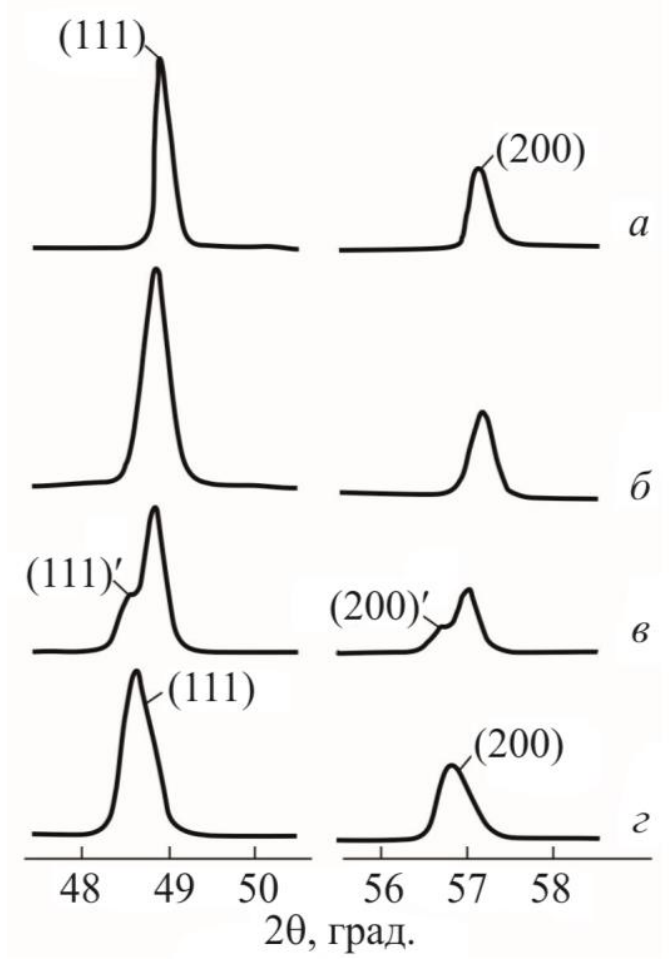

Рис. 4. Рентгеновские дифрактограммы сплава: $a$ - недеформированное состояние; $\sigma$ - деформация трением в воздушной среде; $в$ - деформация трением + оксидирование при $100{ }^{\circ} \mathrm{C}, 1$ ч; 2 - деформация трением + оксидирование при $200{ }^{\circ} \mathrm{C}, 1$ ч, (') - рефлексы модифицированной $\gamma$-фазы $\mathrm{Al}$

Описанные выше процессы хорошо согласуются с эволюцией структуры, наблюдаемой после отжига деформированного трением сплава. Электронно-микроскопическое исследование показало, что после часового оксидирования при $100{ }^{\circ} \mathrm{C}$ сплав $\mathrm{Al}-17 \% \mathrm{Si}$ сохраняет двухфазное нанокристаллическое состояние (рис. $5 a$, б). Кристаллы кремния и зерна алюминия в данном случае имеют размер не более 100 нм, а электронная микродифракция представляет собой кольца Дебая. Внутри зерен матрицы сохраняются скопления дислокаций. Эти факты подтверждают, что процессы термического разупрочнения при температуре оксидирования $100{ }^{\circ} \mathrm{C}$ происходят относительно слабо, что связано с начальной стадией возврата - отдыхом. При повышении температуры оксидирования до $200{ }^{\circ} \mathrm{C}$ происходит активный процесс полигонизации, о чем свидетельствует рост величины зерен до 500 нм и более и уменьшение микротвердости (рис. 2 и 5 г, d). Расшифровка микроэлектронограмм сплава, подвергнутого оксидированию при 100 и $200{ }^{\circ} \mathrm{C}$, показала присутствие рефлексов, принадлежащих окислам - $\mathrm{Al}_{2} \mathrm{O}_{3}$ и $\mathrm{SiO}_{2}$ (рис. 5 в). При отжиге $200{ }^{\circ} \mathrm{C}$ диффузионный распад матрицы сплава, связанный с выделением оксидных фаз, очевидно, соответствует стадии «перестаривания», когда снижается прочность и активизируется рост частиц упрочняющих фаз. 


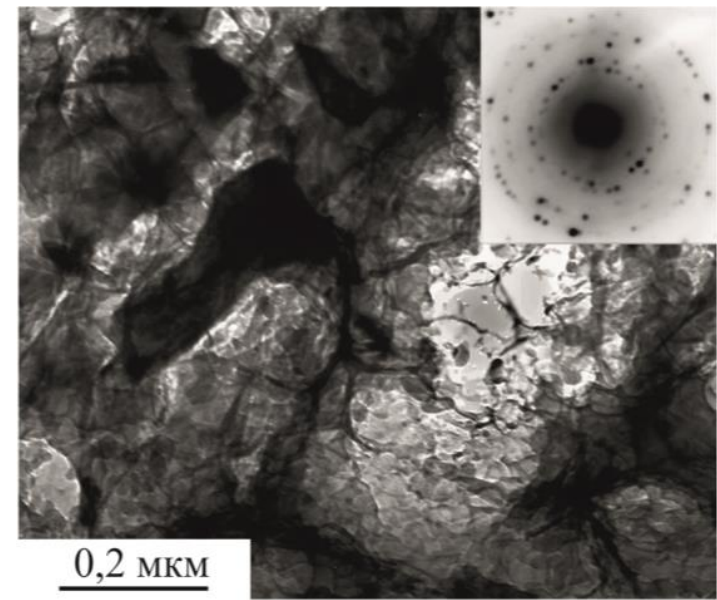

$a$
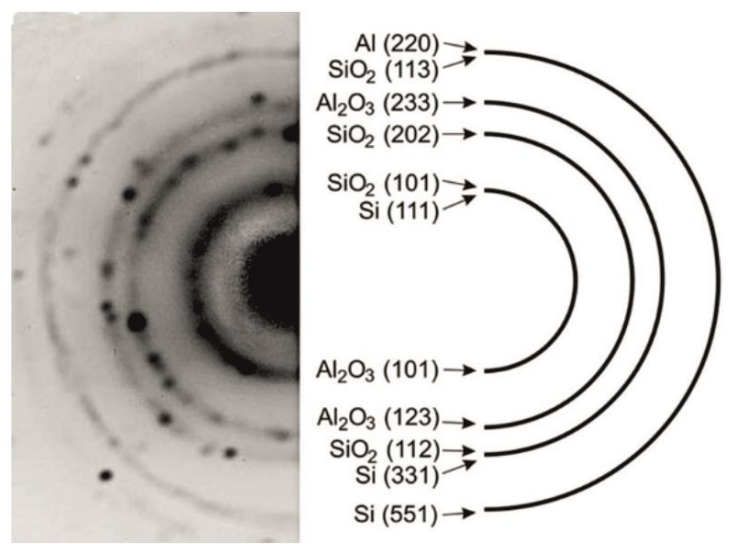

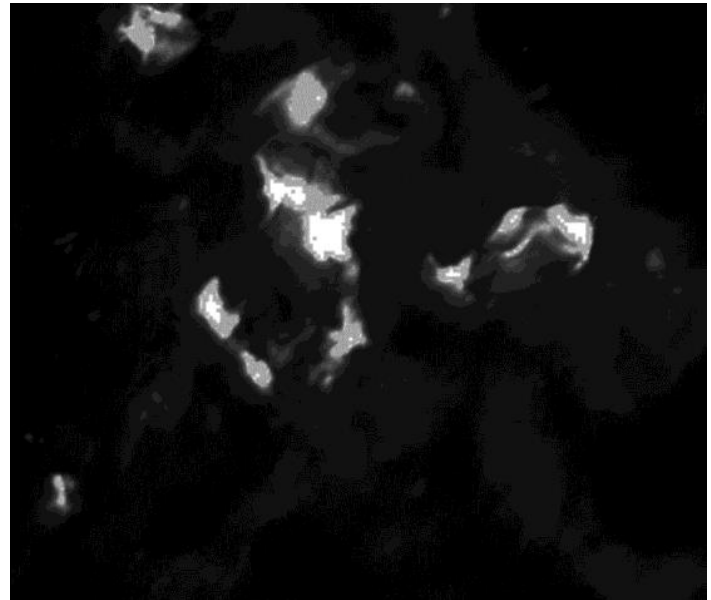

$\sigma$

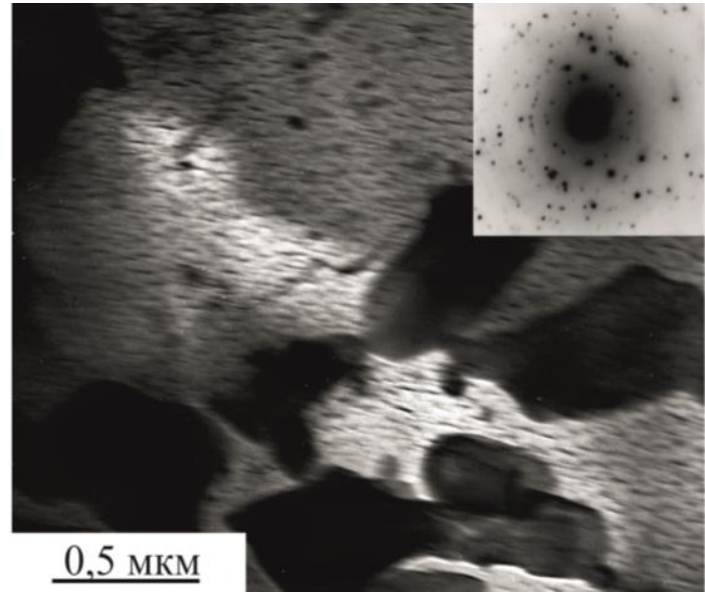

2

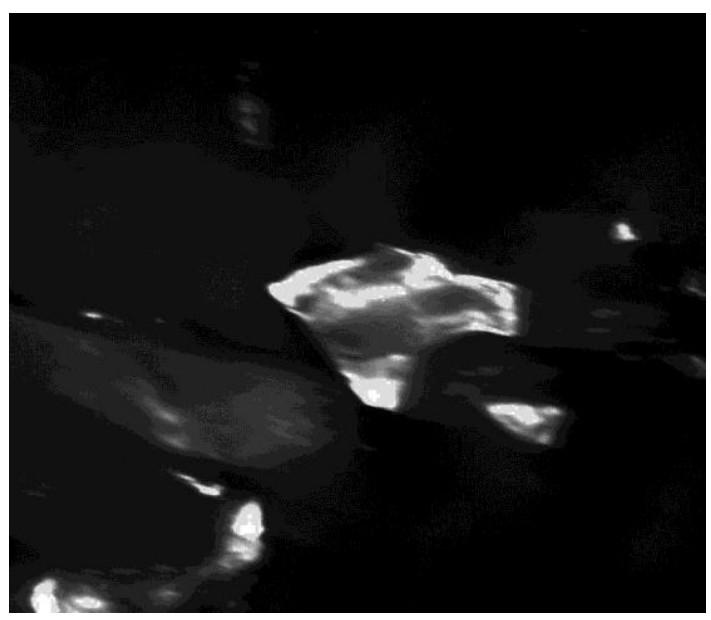

$\partial$

Рис. 5. Структура поверхностного слоя толщиной несколько микрон сплава $\mathrm{Al}-17$ \% Si, подвергнутого деформированию в условиях трения на воздухе и последующему оксидированию при $100(a, \sigma)$ и при $200{ }^{\circ} \mathrm{C}(2, \partial) ; в$ - расшифровка рентгенограммы на вставке рис. $5 a$. Светлопольные $(a, 2)$ и темнопольные $(\sigma, \partial)$ в рефлексе $(111)_{\mathrm{Al}}$ изображения 


\section{4. Заключение}

Деформирование трением скольжения на воздухе при комнатной температуре, а также в среде жидкого азота $\left(-196^{\circ} \mathrm{C}\right)$ формирует в поверхностном слое (толщиной до 10 мкм) силумина нанокристаллическую структуру с неоднородным размером зерен алюминия и кристаллов кремния от нескольких до 100 нм. Криогенная среда (жидкий азот) не повлияла на параметры упрочнения силумина.

Большая деформация в условиях трения, а также большое сродство кислорода к алюминию и кремнию создают условия для формирования в поверхностном слое сплава $\mathrm{Al}-17$ \% Si пересыщенных твердых растворов кислорода в алюминии и кремнии.

Оксидирование при $100{ }^{\circ} \mathrm{C}$ (1 ч) деформированного трением в воздушной среде сплава $\mathrm{Al}-17 \% \mathrm{Si}$ приводит к повышению его микротвердости в результате диффузионного распада (старения) аномально пересыщенных твердых растворов кислорода в алюминии и кремнии и образования их окислов.

\section{Благодарность}

Электронно-микроскопическое исследование проведено в отделе электронной микроскопии ЦКП «Испытательный центр нанотехнологий и перспективных материалов» ИФМ УрО РАН.

Данная работа выполнена в рамках государственного задания по теме «Структура» № 01201463331 .

\section{Литература}

1. Коршунов Л. Г., Макаров А. В., Черненко Н. Л. Нанокристаллические структуры трения в сталях и сплавах, их прочностные и трибологические свойства // Развитие идей академика В. Д. Садовского : сб. науч. трудов. - Екатеринбург. - 2008. - С. 218-241.

2. Dong Y., Bell T. Enhanced wear resistance of titanium surfaces by a new thermal oxidation treatment // Wear. - 2000. - Vol. 238. - P. 131-137.

3. Korshunov L. G., Chernenko N. L. Formation of a wear-resistant nanocrystalline layer strengthened by $\mathrm{TiO}_{2}$ (Rutile) particles on the surface of titanium // Physics of Metals and Metallography. - 2013. - Vol. 114, no. 9. - P. 789-797. - DOI: 10.1134/S0031918X13070065.

4. Metin E., Inal O. T. Kinetics of layer growth and multiphase diffusion in ion nitrided titanium // Metal. Mater. Trans. - 1989. - Vol. 20A, no. 9. - P. 1819-1832.

5. Effect of contact stresses on the phase composition, strength, and tribological properties of nanocrystalline structures formed in steels and alloys under sliding friction / L. G. Korshunov, V. A. Shabashov, N. L. Chernenko, V. P. Pilyugin // Metal Science and Heat Treatment. - 2008. Vol. 5, nos. 11-12. - P. 583-592. - DOI: 10.1007/s11041-009-9103-2.

6. Вол А. Е. Строение и свойства двойных металлических систем. - М. : Государственное издательство физико-математической литературы, 1959. - 755 с.

7. Энциклопедия неорганических материалов : в двух томах. Т. 1. - Киев : Главная редакция украинской советской энциклопедии, 1977. - 840 с.

8. Studying recovery processes in a strain-hardened Al-Mg-Mn-Fe-Si alloy / N. B. Pugacheva, D. I. Vichuzhanin, S. T. Kalashnikov, A. V. Ivanov, S. V. Smirnov, N. Yu. Frolova // Physics of Metals and Metallography. - 2016. - Vol. 117, no. 9. - P. 920-926. - DOI: 10.1134/S0031918X16090076. 